\title{
Perineurial Defect and Peripheral Opioid Analgesia in Inflammation
}

\author{
Irina Antonijevic,' Shaaban A. Mousa, ${ }^{2,3}$ Michael Schäfer,, ${ }^{2,3}$ and Christoph Stein ${ }^{3}$ \\ 'Department of Neurobiology, AFRC Babraham Institute, Babraham, Cambridge CB2 4AT, United Kingdom, 'Behavioral \\ Pharmacology and Genetics Section, Addiction Research Center, National Institute on Drug Abuse, Baltimore, Maryland \\ 21224, and ${ }^{3}$ Department of Anesthesiology and Critical Care Medicine, Johns Hopkins University School of Medicine, \\ Baltimore, Maryland 21287-8711
}

Opioid receptors have been demonstrated on sensory nerves in both inflamed and normal subcutaneous tissue but locally applied opioid agonists produce analgesia in inflamed tissue only. Inflammation confers a disruption of the perineurial barrier that can also be induced deliberately by hyperosmolar solutions. The present study examines at which stage of Freund's adjuvant-induced inflammation peripheral opioid analgesic effects become manifest and whether a perineurial defect contributes to the appearance of such effects. To this end we have monitored the temporal evolution of inflammatory signs (swelling, temperature, hyperalgesia) and of peripheral antinociceptive effects (by the paw pressure test) of $\mu-, \delta-$, and $\kappa$-selective opioids. Using horseradish peroxidase histochemistry, the perineurial barrier was assessed in normal and inflamed tissue and following its artificial disruption by hyperosmolar saline and mannitol in vivo. Finally, we sought to elicit analgesia in normal tissue by the concomitant application of mannitol and receptorselective opioids or by an extremely lipophilic opioid agonist (fentanyl). We found that peripheral opioid antinociception and perineurial leakage occur simultaneously at a very early stage (within $12 \mathrm{hr}$ ) of the inflammatory reaction and that both can be mimicked by the administration of hyperosmolar solutions in normal tissue. Fentanyl produced peripheral antinociception in noninflamed tissue that was potentiated by mannitol or inflammation. Our findings demonstrate that the perineurium is a crucial determinant for peripheral opioid analgesia and that the efficacy of locally applied hydrophilic or lipophilic neuromodulatory compounds can be Improved dramatically by the concomitant modulation of perineurial permeability. Furthermore, these observations indicate an unrestricted transperineurial passage for peptides in inflammation and thus add a further integral component to our previously outlined concept of a direct communication between immune cell-derived endogenous opioid peptides and sensory nerves resulting in the inhibition of inflammatory pain.

\footnotetext{
Received June 2, 1994; accepted June 15, 1994
}

This work was supported by NIH/NINDS Grant RO1 NS32466. This work was initiated at the Department of Neuropharmacology, Max-Planck-Institut für Psychiatrie, Martinsried, Germany. We thank Drs. W. Risau and A. Herz for stimulating discussions, Dr. S. R. Goldberg for continuous support, and Mrs. U. Bäuerle for artwork.

Correspondence should be addressed to Christoph Stein, Department of Anesthesiology, Johns Hopkins Hospital, Tower 711, Baltimore, MD 21287-8711. Copyright (C) 1995 Society for Neuroscience $0270-6474 / 95 / 150165-08 \$ 05.00 / 0$
IKey words: pain, opioids, local analgesia, antinociception, inflammation, perineurium, blood-nerve barrier, peptides, horseradish peroxidase, hyperosmolar solutions, mannitol, lipophilic compounds, fentanyl]

A growing number of both experimental and clinical studies demonstrate that locally administered opioid agonists can produce pronounced analgesic effects by interacting with peripheral opioid receptors in inflamed tissue. Such receptors are present on peripheral sensory nerves where they can modulate both afferent and efferent neuronal functions to eventually result in antinociception. Three different types of opioid receptors $(\mu, \delta$, $\kappa)$ appear to mediate such effects (for reviews, see Barber and Gottschlich, 1992; Stein, 1993).

The fact that peripheral antinociceptive effects of opioid agonists are pronounced in inflamed tissue but negligible under normal conditions (Stein, 1993), suggests an inflammation-induced process. There are several hypotheses. First, an increase in de novo synthesis and peripheral axonal transport of opioid receptors (Hassan et al., 1993; Schäfer et al., 1994b). Second, an activation of opioid receptors that are preexistent on sensory nerves, but inactive or inaccessible by virtue of a perincurial barrier under normal conditions (Rechthand and Rapoport, 1987; Olsson, 1990). At later stages of an inflammatory reaction, the first hypothesis could serve as an explanation. At earlier stages, however, an inflammation-induced disruption of the perineurial barrier (de la Motte et al., 1975; Olsson, 1990) and a subsequent facilitated access for agonists seems more likely. Such leakage of the perineurium can also be produced experimentally by the extraneural application of hyperosmolar solutions (Kristensson and Olsson, 1976; Weerasuriya et al., 1979; Rechthand and Rapoport, 1987).

The present study sought to examine at which stage of Freund's adjuvant-induced inflammation peripheral antinociceptive effects of opioids become manifest and whether a deficiency of the perineurial barrier could contribute to such effects. To this end we have (1) monitored the temporal evolution of inflammatory signs and, in parallel, of peripheral antinociceptive effects of $\mu-, \delta$, and $\kappa$-selective opioid agonists, (2) examined the perineurial permeability to horseradish peroxidase histochemically under normal and inflammatory conditions, and following the in vivo administration of different hyperosmolar solutions, and (3) tested whether it is possible to produce peripheral opioid effects in noninflamed tissue by an extremely lipophilic compound or after artificial disruption of the perineurial barrier by a locally applied hyperosmolar solution. 


\section{Materials and Methods}

Subjects. Experiments were performed in male Wistar rats (Savo Ivanovas, Kisslegg, Germany, and Charles River Laboratories) weighing 180-230 gm, housed individually in cages lined with sawdust. Standard rodent chow and water were available ad libitum. Room temperature and relative humidity were maintained at $22 \pm 0.5^{\circ} \mathrm{C}$ and $40-50 \%$, respectively. A $12: 12$ hr (8 A.M./8 P.M.) light/dark cycle was used and testing was conducted in the light phase. Animals were handled at least three times before any testing was performed. The guidelines on ethical standards for investigations of experimental pain (Wall, 1993) were followed. Animal facilities were accredited by the AAALAC and experiments were approved by the IACUC of ARC/NIDA/NIH in accordance with ILAR, NRC, Department of Health, Education and Welfare, Publication (NIH) 85-23, revised 1985.

Induction of inflammation. The inflammatory agent used was modified Freund's complete adjuvant (FCA), containing 0,1\% heat-killed and dried Myocobacterium butyricum in $85 \% \mathrm{Marcol} 52$ and $15 \%$ Aracel A mannide monooleate emulsifier (Calbiochem, La Jolla, CA). Rats received an intraplantar injection of $0.15 \mathrm{ml}$ of this suspension into the right hindpaw under brief ether anesthesia.

Drugs and their administration. The following drugs were used: (DAla 2, $N$-methyl-Phe 4, Gly-ol 5)-enkephalin (DAGO) (Bachem AG, Bubendorf, Switzerland), [D-Pen 2,5]-enkephalin (DPDPE) (Bachem), trans-( \pm )-3,4-dichloro- $N$-methyl- $N$-[2-(1-pyrrolidinyl)cyclohexyl]benzene-acetamide (U-50,488H) (Upjohn, Kalamazoo, MI), fentanylcitrate (Research Biochemicals International, Natick, MA), (-)-naloxone-HCl (DuPont, Geneva, Switzerland), D-(-)-mannitol (C6H14O6, $182.17 \mathrm{gm} / \mathrm{mol}$ ) (Merck, Darmstadt, Germany), horseradish peroxidasc (HRP) type II (Sigma, St. Louis, MO), ether and halothane (Hoechst, Frankfurt, Germany). Doses were calculated as the free base. U-50,488H, fentanyl, and naloxone were dissolved in sterile normal saline; DAGO, DPDPE, and mannitol were dissolved in sterile water.

Intravenous (i.v.) injections were given in a volume of $0.2 \mathrm{ml}$ via a 24-gauge indwelling plastic cannula (Insyte, Becton Dickinson, Sandy, UT) into a tail vein under brief halothane anesthesia. Intraplantar (i.pl.) injections were given in a volume of $0.2 \mathrm{ml}$ under brief ether anesthesia. Two minutes after termination of either anesthetic the animals were fully awake and no behavioral anomalies were detected at any time. The mannitol solution had a pH of 6.79 and a temperature of $37^{\circ} \mathrm{C}$ and was injected together with opioid agonists and/or antagonists over $20-$ $30 \mathrm{sec}$. All doses and times of administration were based on pilot and previous experiments (Stein et al., 1988; 1989).

Parameters of inflammation. Paw volume, paw temperature, and hyperalgesia (paw pressure thresholds) were assessed before and 1, 6, 12, and $24 \mathrm{hr}$, and $4 \mathrm{~d}(96 \mathrm{hr})$ after FCA injection. The volume was assessed by submerging the hindpaws to the tibiotarsal joints into a water filled Perspex cell of a plethysmometer (Ugo Basile, Comerio, Italy). The volume of displacement, which is equal to the paw volume, was then read on a digital display. The surface temperature of the plantar skin was measured with an Infrared radiation thermometer (Ultrakust, Ruhmannsfelden, Germany). These parameters were taken twice and the average calculated. Paw pressure thresholds (PPT) were measured as described below.

Algesiometric testing. Antinociceptive effects of drugs were evaluated using the paw pressure test. The animal was gently restrained under papcr wadding and incremental pressurc applicd via a wedge-shaped blunt piston onto an area of $1.75 \mathrm{~mm}^{2}$ of the dorsal surface of the hindpaw by means of an automated gauge (Ugo Basile, Comerio, Italy). The pressure required to elicit paw withdrawal (PPT), was determined. A cutoff of $250 \mathrm{gm}$ was employed. Three consecutive trials, separated by $10 \mathrm{sec}$, were conducted and the average calculated. The same procedure was then performed on the contralateral side; the sequence of sides was altered between subjects to preclude "order" effects. Separate groups of animals were used for each treatment. PPTs were assessed before injection (baseline) and were reevaluated 3-5, 10, and $20 \mathrm{~min}$ thereafter. The observer was blind to the experimental condition employed.

Histochemistry. To assess perineurial permeability, rats were treated with HRP according to the protocols outlined below. As described by Rosene and Mesulam (1978), fixation of paw tissue was initiated under pentobarbital anesthesia $(50 \mathrm{mg} / \mathrm{kg}$, intraperitoneal) by perfusion via the ascending aorta with $50 \mathrm{ml}$ of normal saline, followed by $400 \mathrm{ml}$ of $1.25 \%$ glutaraldehyde and $1 \%$ paraformaldehyde in $0.1 \mathrm{~m}$ phosphate buffer ( $\mathrm{pH} 7.4$ at $21^{\circ} \mathrm{C}$ ) and $200 \mathrm{ml}$ of $5 \%$ sucrose in $0.1 \mathrm{M}$ phosphate- buffered saline at $4^{\circ} \mathrm{C}$. Skin and adjacent subcutaneous tissue were dissected from the plantar surface of the hindpaws and stored overnight in $0.1 \mathrm{M}$ phosphate buffer with $20 \%$ sucrose at $4^{\circ} \mathrm{C}$. To visualize HRP, transverse sections $(30 \mu \mathrm{m})$ of subcutaneous tissue were mounted on chrome-alum subbed slides (Streinzer and Krammer, 1986). As described by Malmgren and Olsson (1978) they were incubated in the dark with $200 \mathrm{mg}$ of diaminobenzidine tetrahydrochloride in $100 \mathrm{ml}$ of cacodylate buffer $(0.1 \mathrm{M}, \mathrm{pH} 5.1)$ and $1 \%$ hydrogen peroxide for $30 \mathrm{~min}$ at room temperature. The sections were then washed in cacodylate buffer, left in air to dry at room temperature, and finally coverslipped with entelan (Merck). To demonstrate specificity of staining, HRP was omitted in control experiments.

Experimental protocols. The first set of experiments sought to assess the occurrence of peripheral opioid antinociceptive effects in relation to the development of inflammatory signs. In one group of animals $(n$ $=12$ ) paw temperature and volume were measured before and 1, 6, 12, $24 \mathrm{hr}$ and $4 \mathrm{~d}$ after FCA inoculation. At the same intervals, antinociceptive effects of intraplantar $\mu-, \delta-$, and $\kappa$-selective agonists were examined. Separate groups of rats $(n=7-12)$ received into both hindpaws either DAGO $(0.004 \mathrm{mg})$, DPDPE $(0.04 \mathrm{mg}), \mathrm{U}-50,488 \mathrm{H}(0.04 \mathrm{mg})$, or saline. To rule out a central site of action, separate groups of rats $(n=$ $6-8)$ received the total dose of each agonist $(0.008 \mathrm{mg}$ DAGO, $0.08 \mathrm{mg}$ DPDPE, $0.08 \mathrm{mg} \mathrm{U}-50,488 \mathrm{H}$ ) intravenously $12 \mathrm{hr}$ post FCA inoculation. Naloxone reversibility of agonist effects at $12 \mathrm{hr}$ after FCA injection was assessed in separate groups $(n=6)$ : Agonists (vide supra) were administered concomitantly with naloxone i.pl. in a total volume of 0.2 $\mathrm{ml}$. Doses of naloxone were $0.005 \mathrm{mg}$ (with DAGO and $\mathrm{U}-50,488 \mathrm{H}$ ) and $0.04 \mathrm{mg}$ (with DPDPE).

The second set of experiments sought to examine perineurial permeability histochemically. Rats received intraplantar injections of HRP $(8 \mathrm{mg}$ in $0.1 \mathrm{ml}$ of normal saline) into both hindpaws $12 \mathrm{hr}(n=10)$ or on day 4 after inoculation with FCA $(n=10)$. Thirty or 60 min later the animals (groups of five each) were anesthetized and perfused. To study the effects of hyperosmolar solutions on perineurial permeability in normal tissue, untreated rats received bilateral intraplantar HRP (8 $\mathrm{mg})$. Mannitol $(0.5 \mathrm{M} ; 0.2 \mathrm{ml}$; right paw) or normal saline $(0.2 \mathrm{ml}$, left paw) was given simultaneously with $\operatorname{HRP}(n=10)$ or 30 min later $(n$ $=10$ ). Thirty minutes after the last treatment the animals were anesthetized and perfused. Another group $(n=10)$ received hypertonic $(20 \%)$ saline $(0.2 \mathrm{ml})$ into the right and normal saline into the left paw, followed by bilateral HRP $(8 \mathrm{mg}) 60 \mathrm{~min}$ later. Sixty minutes after the last treatment the animals were anesthetized and perfused.

The third sct of cxperiments sought to assess whether opioid-induced antinociception in inflamed paws could be mimicked in noninflamed tissue by concomitant administration of hyperosmotic mannitol. After baseline PPT measurement four groups of animals $(n=6-8)$ without FCA pretreatment received $0.1 \mathrm{ml}$ mannitol in different concentrations $(0,0.5,1$, or $2 \mathrm{~mol} / \mathrm{liter}$ ) together with $0.1 \mathrm{ml}$ of sterile water (left paw) or DAGO $(0.004 \mathrm{mg})$ (right paw). Three minutes later PPT were taken. To determine the time of maximum effect of mannitol, a group of normal rats $(n=7)$ was injected with $0.5 \mathrm{M}$ mannitol into both hindpaws after determination of baseline PPT. Five minutes later animals received DAGO $(0.004 \mathrm{mg})$ into the right paw. After another $5 \mathrm{~min}$ (i.e., $10 \mathrm{~min}$ after the mannitol injection) PTT were reevaluated.

The effect of mannitol-opioid combinations in rats with inflamed paws was examined in the following experiment. At $12 \mathrm{hr}$ and $4 \mathrm{~d}$ after FC $\Lambda$ inoculation, respectively, six groups $(n=6-7)$ reccived $1 \mathrm{M}$ mannitol together with either DAGO, DPDPE, or U-50,488H (in the above doses) into inflamed and noninflamed paws.

The opioid receptor specificity of the effects of mannitol-opioid combinations in noninflamed paws was tested in another experiment. Separate groups of normal rats $(n=6-7)$ received either mannitol, mannitol plus DAGO, DPDPE or U-50,488H, or mannitol plus either agonist plus naloxone i.pl.. To keep a total injection volume of $0.2 \mathrm{ml}$ in the latter experiment, the following concentrations of drugs were applied: mannitol $(0.1 \mathrm{ml}, 1 \mathrm{M})$; DAGO $(0.004 \mathrm{mg} / 0.05 \mathrm{ml})$, naloxone $(0.005$ $\mathrm{mg} / 0.05 \mathrm{ml}) ;$ DPDPE $(0.04 \mathrm{mg} / 0.05 \mathrm{ml})$, naloxone $(0.04 \mathrm{mg} / 0.05 \mathrm{ml})$; I $-50,488 \mathrm{H}(0.04 \mathrm{mg} / 0.05 \mathrm{ml})$, naloxone $(0.005 \mathrm{mg} / 0.05 \mathrm{ml})$.

The final experiment sought to examine whether a lipophilic opioid agonist produced peripheral antinociceptive effects in normal tissue, whether these could be further enhanced by mannitol and to comparc these effects to those occurring in inflamed tissue. Seven separate groups of normal rats $(n=6-7)$ received different doses of fentanyl $(0.0001-$ $0.002 \mathrm{mg} / 0.1 \mathrm{ml})$ with or without mannitol $(0.1 \mathrm{ml}, 1 \mathrm{~m})$ into one and normal saline into the contralateral hindpaw. Three groups of FCA- 

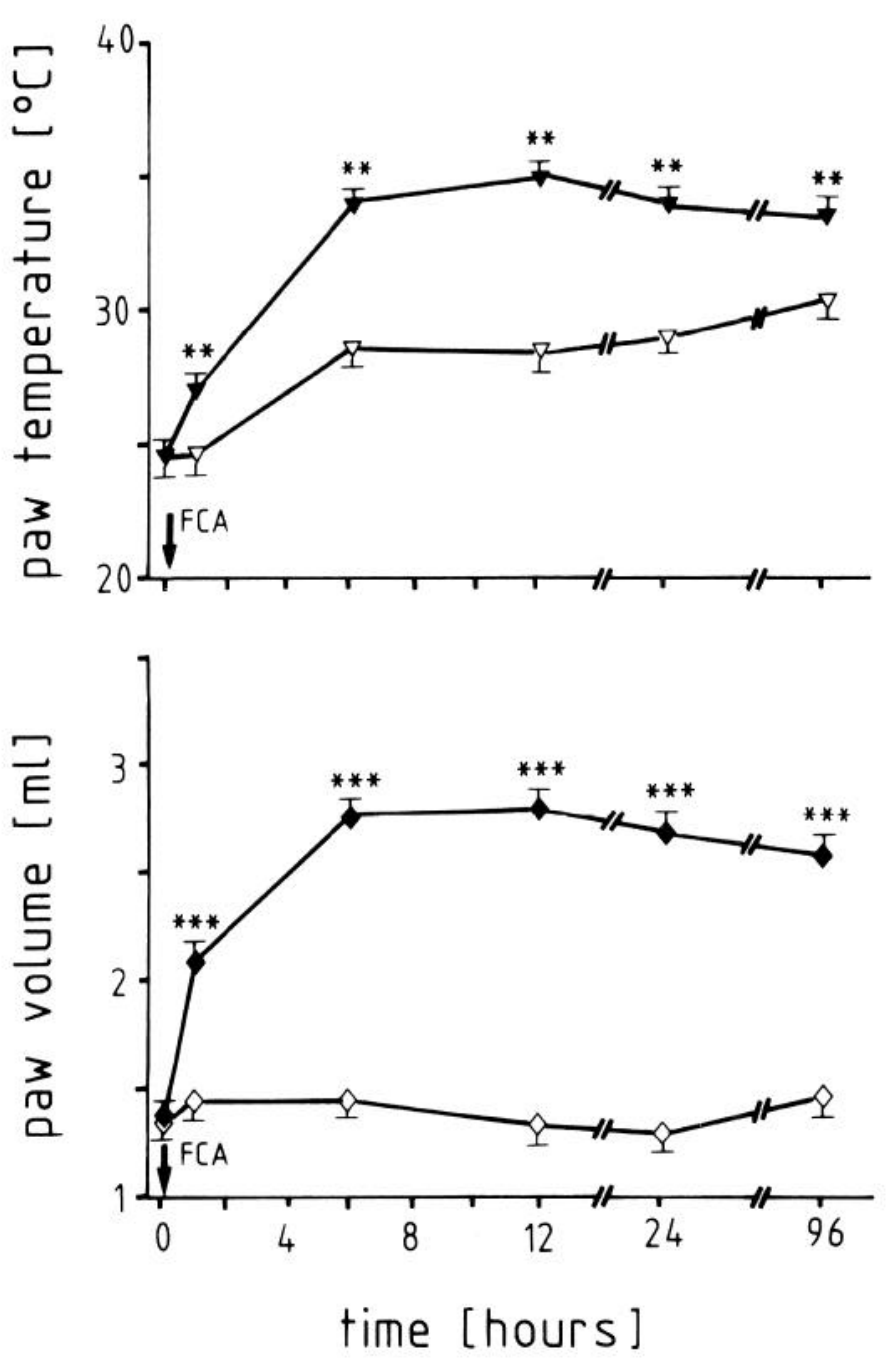

Figure 1. Paw volume and temperature in inflamed (solid symbols) and noninflamed (open symbols) hindpaws before ( $0 \mathrm{hr}$ ) and 1, 6, 12, 24 , and $96 \mathrm{hr}$ after induction of inflammation. Values are means \pm SEM. Significance of differences between left and right paws is *, $p<$ $0.05 ;^{* *}, p<0.005 ;{ }^{* * *}, p<0.001(n=12$, Wilcoxon test; see text $)$.

treated rats received different doses of fentanyl $(0.0001-0.0012 \mathrm{mg} / 0.1$ $\mathrm{ml}$ ) into both hindpaws. PPT were assessed after $5 \mathrm{~min}$.

Data analysis. Two-sample comparisons were made using the Wilcoxon test for dependent and the Mann-Whitney $U$ test for independent data. Multiple comparisons and post hoc tests were performed with the Friedman and Scheffe tests for dependent and the Kruskal-Wallis and Dunn tests for independent data. The Bonferroni correction was applied as appropriate (Zar, 1984). Dose-response curves were compared using a two-factor analysis of variance (ANOVA). Differences were considered significant if $p<0.05$ (two-tailed). The elevation in PPT was expressed as percentage of the maximum possible effect (\% MPE) according to the following formula: (PPT postinjection - basal PPT): (250 gm - basal PPT). Mean values and the standard error of the mean (SEM) are given.

\section{Results}

Signs of inflammation appeared in the following sequence after inoculation with FCA. The volume and temperature of the inoculated paws increased significantly from baseline levels as early as $1 \mathrm{hr}$. At $12 \mathrm{hr}$ both parameters reached a maximum (Friedman test, $p<0.005$; Scheffe test $p<0.05$ ) and did not significantly change thereafter (Friedman test, NS). The volume of noninflamed paws did not change during the observation

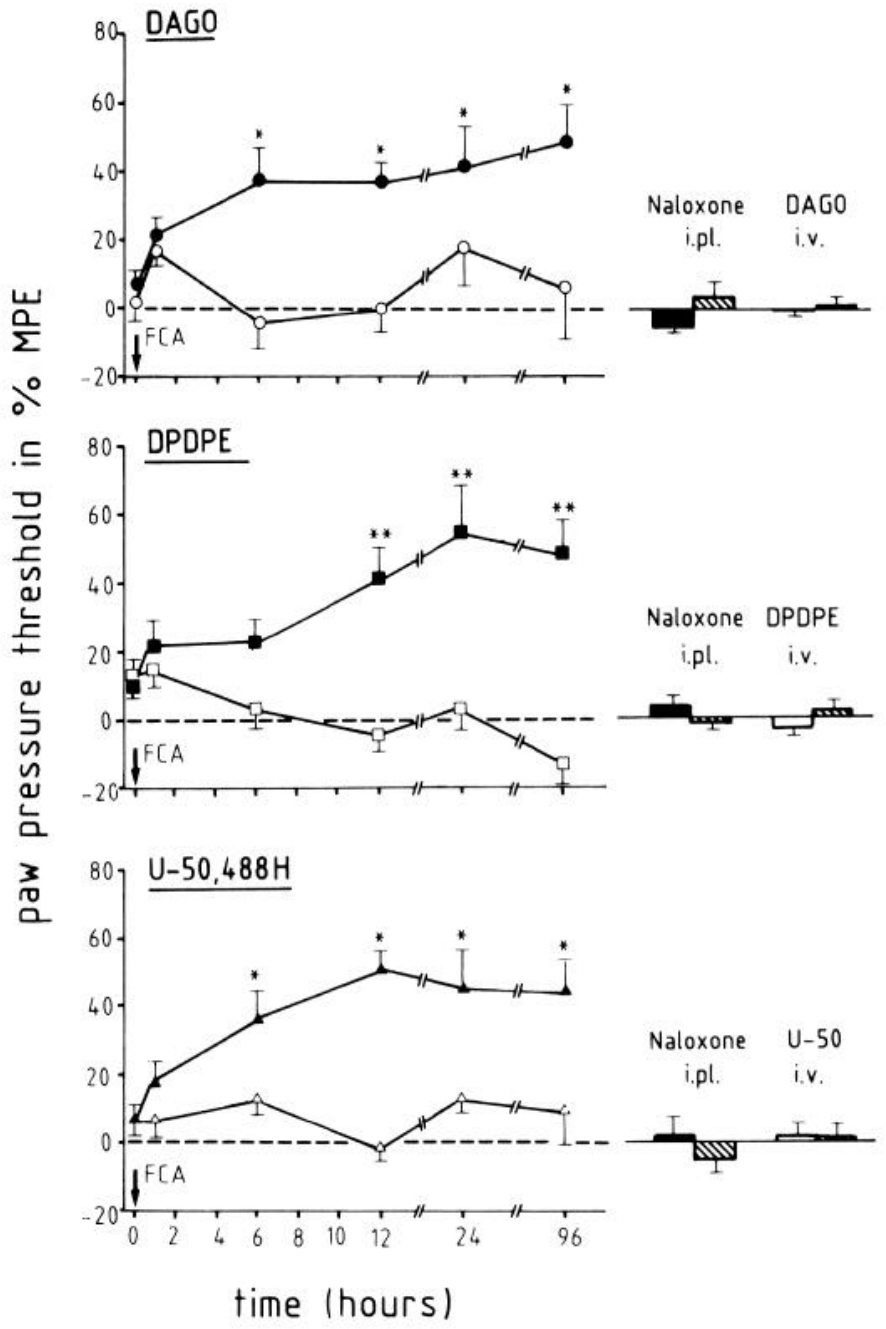

Figure 2. PPT alterations (in \% MPE) after intraplantar administration of $0.004 \mathrm{mg}$ of DAGO, $0.04 \mathrm{mg}$ of DPDPE, and $0.04 \mathrm{mg}$ of U-50,488H before $(0 \mathrm{hr})$ and $1,6,12,24$, and $96 \mathrm{hr}$ after induction of inflammation in inflamed (solid symbols) and noninflamed (open symbols) paws. Effects of naloxone given concomitantly with the above agonists in inflamed (hatched bars) and noninflamed (solid bars) paws, and effects of intravenous administration of the above agonists in inflamed (hatched bars) and noninflamed (open bars) paws at $12 \mathrm{hr}$ after FCA inoculation. Peak effects (3-5 min after drug injection) are shown. Values are means \pm SEM. Significance of differences is ${ }^{*}, p<0.01 ;{ }^{* *}, p<0.001(n=$ 6-12, Kruskal-Wallis test, $U$ test; see text).

period (Friedman test, NS). The temperature of noninflamed paws began to increase slightly at $6 \mathrm{hr}$ (Friedman and Scheffe test, $p<0.05$ ), probably due to a general hyperthermia caused by the inflammation, but remained significantly below that of inoculated paws at all time points (Wilcoxon test, $p<0.005$ ) (Fig. 1). PPT values before inoculation with FCA were similar in both paws $(87.8 \pm 1.0 \mathrm{gm}$ and $90.2 \pm 4.7 \mathrm{gm}$, respectively). After onset of inflammation basal PPT did not significantly change in noninflamed paws $(86.8 \pm 4.2 \mathrm{gm})$ and decreased in inflamed paws to a minimum of $59.9 \pm 3.0 \mathrm{gm}$ (Wilcoxon test, $p<0.05)$ at $12 \mathrm{hr}$. Thereafter no significant changes were observed in either paw (Friedman test).

The temporal evolution of peripheral opioid antinociception is shown in Figure 2. The first significant elevation in PPT upon opioid administration was observed at $6 \mathrm{hr}$ for DAGO and $\mathrm{U}-50,488 \mathrm{H}$ and at $12 \mathrm{hr}$ for DPDPE (Kruskal-Wallis test, Dunn 

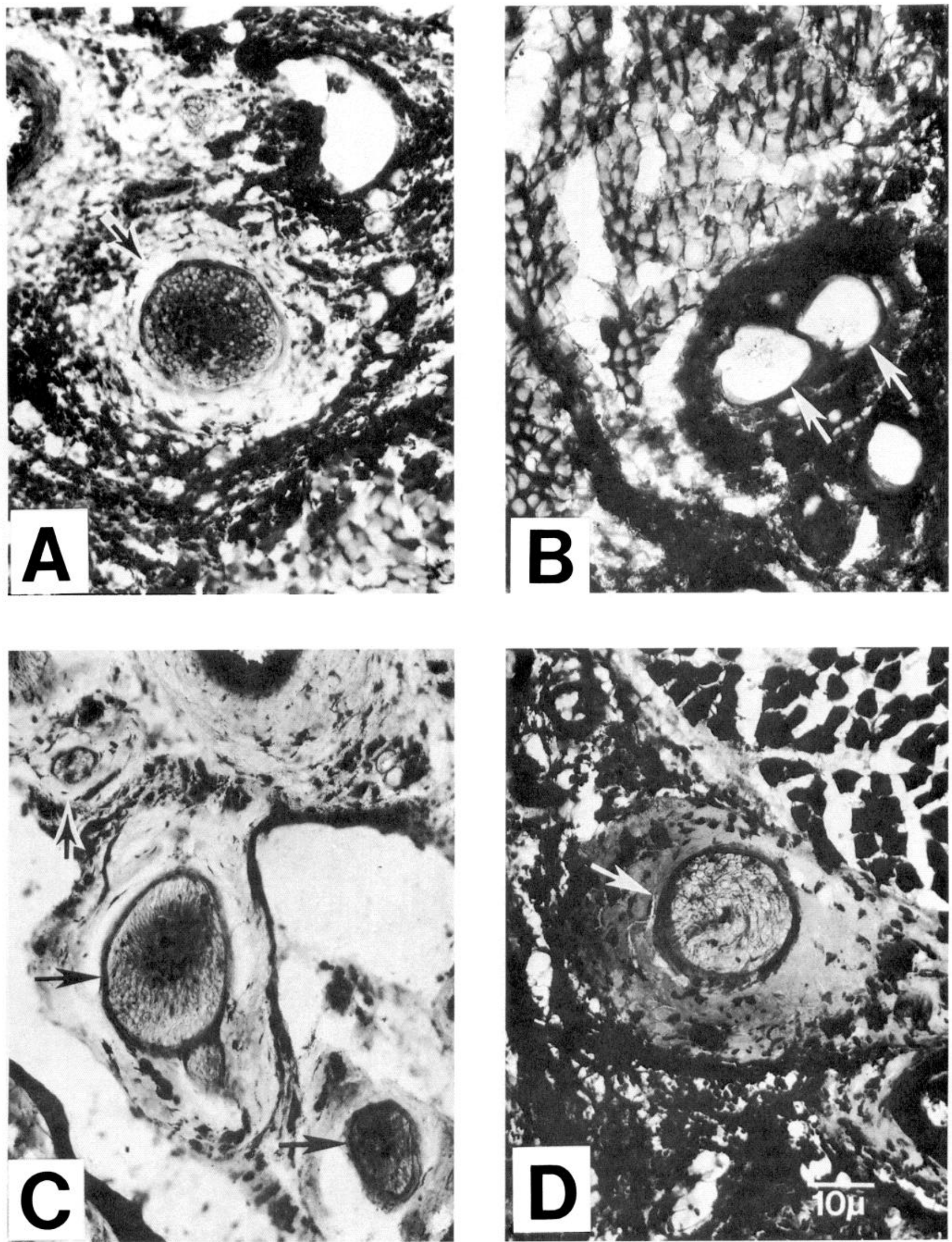

Figure 3. Cross-sections of plantar subcutaneous paw tissue. After intraplantar injection of HRP, reaction products are seen in epineurial connective tissue and in perineurium $(A-D)$. Endoneurium is stained only in inflamed paws $(A)$ and after intraplantar injection of mannitol $(C)$ or hypertonic saline $(D)$, but not in noninflamed paws $(B)$. Staining patterns and cellular infiltration in inflamed tissue $(A)$ were similar at $12 \mathrm{hr}$ and at $4 \mathrm{~d}$ after FCA. Hypertonic solutions did not induce inflammatory cell infiltration $(C, D)$. 


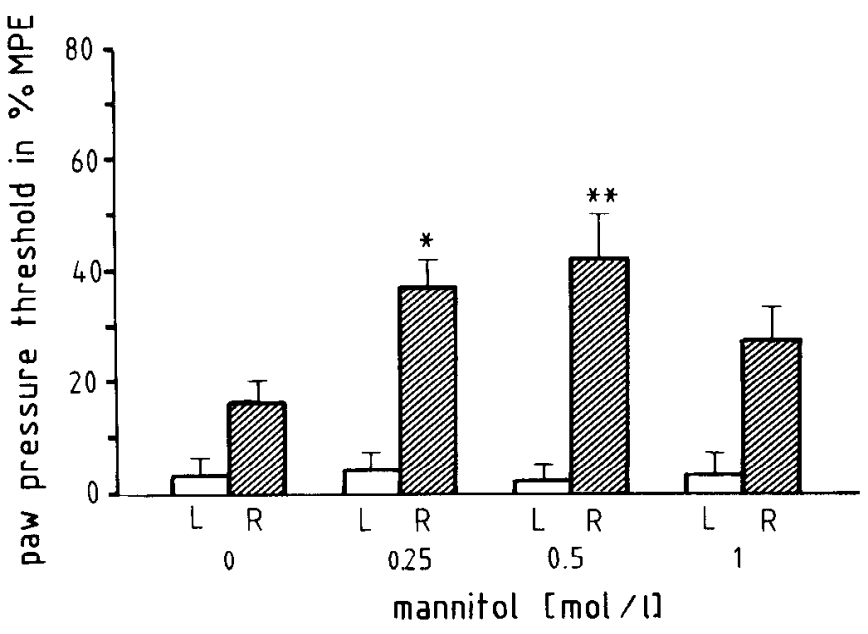

Figure 4. Concentration-response relationship of antinociceptive effect of mannitol combined with DAGO $(0.004 \mathrm{mg}$ ) (hatched bars) and effects of mannitol alone (open bars) in noninflamed paws. Peak effects ( 3 min after drug injection) are shown. Values are means \pm SEM. Significance of differences: ${ }^{*}, p<0.05 ;{ }^{* *}, p<0.005(n=7$, KruskalWallis- and Dunn-test)

test, $p<0.01)$ in inflamed paws. Thereafter PPT elevations remained stable (Kruskal-Wallis test, NS) (Fig. 2). In noninflamed paws neither agonist elicited significant changes in PPT (Kruskal-Wallis test, NS) (Fig. 2). Saline had no effect on PPT in either noninflamed or inflamed paws (not shown), neither had intravenous administration of agonists ( $U$ test, NS, compared to saline) (Fig. 2). The antinociceptive effects of all three opioid agonists in inflamed paws were completely reversible by concomitant administration of naloxone ( $U$ test, NS, compared to saline) (Fig. 2). Naloxone alone does not alter PPT at these doses (Stein et al., 1989). Taken together, these data demonstrate a parallel appearance of inflammatory signs and peripheral opioid receptor-specific antinociceptive effects for all three agonists.

Perineurial permeability patterns are shown in Figure 3 . Both at $12 \mathrm{hr}$ and at $4 \mathrm{~d}$ after FCA, intense and homogeneous endoneurial staining was found in numerous nerve branches 60 min after subcutaneous injection of HRP (Fig. $3 A$ ). At $30 \mathrm{~min}$ after injection, endoneurial tracer was less concentrated and present in fewer and smaller nerves (not shown). In noninflamed paws, the reaction product was diffusely distributed in epineurial connective tissue and in the outer parts of the perineurium with an abrupt difference in staining intensity at the level of the inner layer of the perineurium (Fig. $3 B$ ). Regardless of the time lag after HRP injection, no endoneurial tracer could be detected in the underlying endoneurium (Fig. $3 B$ ). Locally applied mannitol (but not normal saline), when injected 30 min after HRP into noninflamed tissue, resulted in strong homogeneous endoneurial staining (Fig. $3 C$ ) without evidence for an inflammatory reaction (e.g., cellular infiltration). Endoneurial reaction products were fewer and less intensc when mannitol was given earlier (not shown). Similar results were found in rats treated with hypertonic saline (Fig. 3D). In some places tracer was concentrated in intensely staining bodies, probably due to its intracellular accumulation. In control experiments only sporadic staining of erythrocytes or macrophages was seen, presumably representing endogenous peroxidase (not shown).

The third set of experiments demonstrates that the antinociceptive effects of opioids in inflamed paws can be mimicked

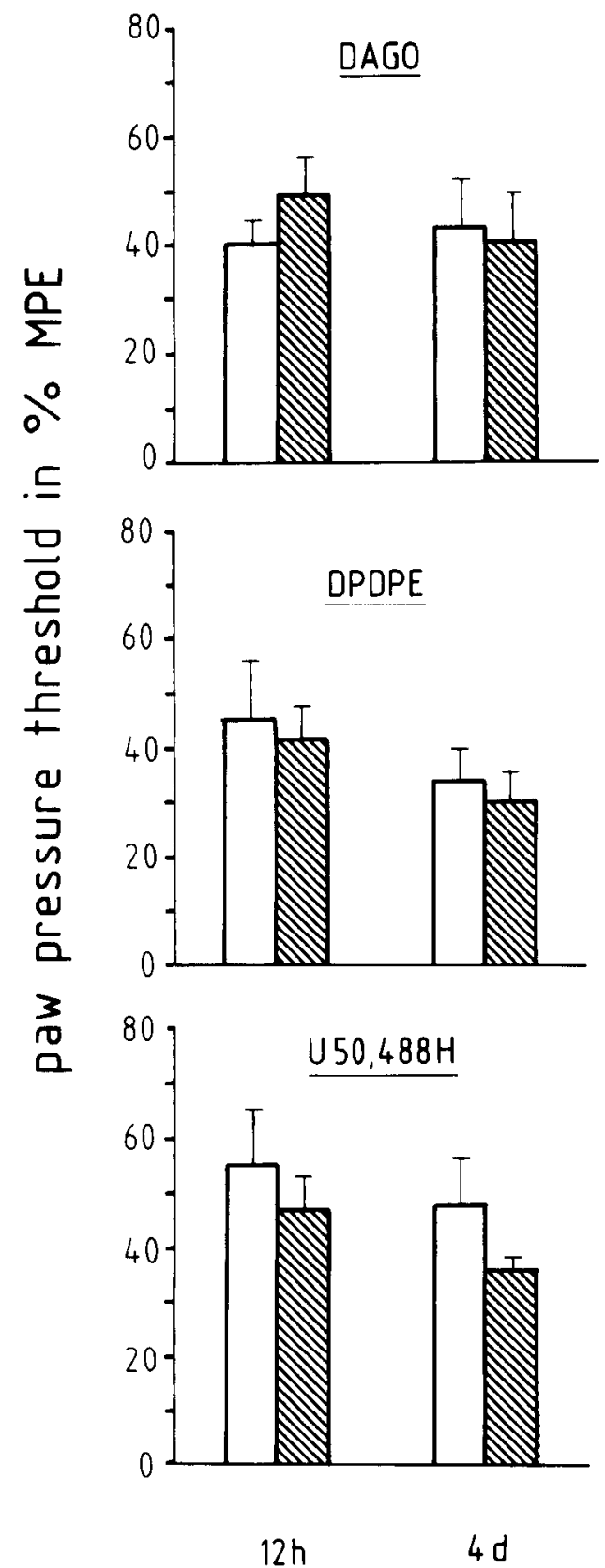

Figure 5. Antinociceptive effects in noninflamed (open bars) and inflamed (hatched bars) paws after concomitant intraplantar injection of mannitol with either DAGO $(0.004 \mathrm{mg})$, DPDPE $(0.04 \mathrm{mg})$ or U-50,488H $(0.04 \mathrm{mg})$. Separate groups were examined at $12 \mathrm{hr}$ or $4 \mathrm{~d}$ after induction of inflammation. Peak effects ( $3 \mathrm{~min}$ after drug injection) are shown. Values are means $\pm \operatorname{SEM}(n=6-7$, Wilcoxon-test, NS).

in noninflamed paws by concomitant application of hyperosmolar mannitol. In normal rats, PPT elevations were significant following the addition of $0.25 \mathrm{M}$ and maximal after the addition of $0.5 \mathrm{M}$ mannitol to DAGO (Kruskal-Wallis and Dunn test, $p$ $<0.05$ ) and declined at higher concentrations (Fig. 4). No effect was seen in paws injected with mannitol alone (Kruskal-Wallis test, NS) (see Figs. 4, 6). When the mannitol injection preceded the DAGO administration by 5 min, no increase in PPT was detected (data not shown).

All three opioid agonists, in combination with mannitol, produced PPT elevations in noninflamed paws that were compa- 


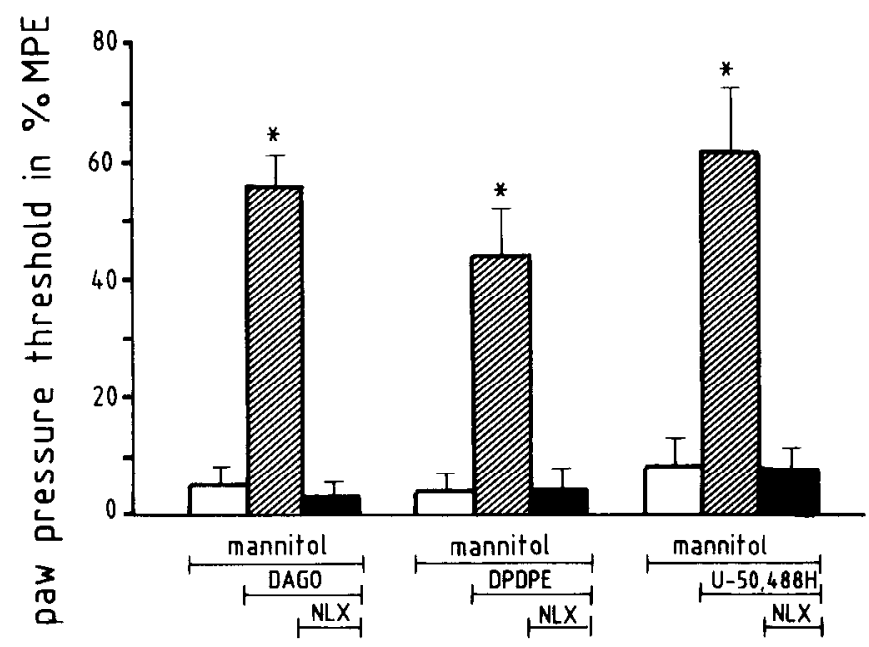

Figure 6. Antinociceptive effects of mannitol (open bars), mannitol with opioid agonists (hatched bars) and the latter combination with naloxone (solid bars) in normal rats. For doses see text. Peak effects (3 min after drug injection) are shown. Values are means \pm SEM. Significance of differences is ${ }^{*}, p<0.05(n-6-7$, Kruskal-Wallis and Dunn test).

rable to those in inflamed paws at $12 \mathrm{hr}$ and $4 \mathrm{~d}$ after inoculation (Wilcoxon test, NS) (Fig. 5). The addition of mannitol to opioids did not alter their antinociceptive effects in inflamed paws ( $U$ test, NS, compare Fig. 5 with Fig. 2).

In normal rats, elevations of PPT similar to those described above were elicited by intraplantar mannitol-opioid combinations (Fig. 6). These effects were completely reversible by naloxone and mannitol alone was inactive (Kruskal-Wallis test, Dunn test, $p<0.05$ ) (Fig. 6). Taken together, these results indicate that, while mannitol itself has no effect on PPT, it allows opioid agonists to induce antinociception through interaction with opioid receptors, independent of the inflammatory process.

Fentanyl produced dose-dependent elevations of PPT in the drug-treated but not in the contralateral saline-treated paw of normal rats. Mannitol significantly potentiated these effects ( $p$ $<0.005$, two-factor ANOVA) while the saline-treated paw remained unaffected. In FCA-treated rats, significantly lower amounts ( $p<0.005$, two-factor ANOVA) of fentanyl produced dose-dependent antinociceptive effects in inflamed paws, while the same dose range was ineffective in noninflamed paws. These effects were similar (two-factor ANOVA, NS) to those elicited by mannitol-fentanyl combinations in normal rats (Fig. 7). These results indicate that a lipophilic opioid can reach the endoneurium to produce peripherally mediated antinociception under normal conditions, and that its transperineurial passage is markedly facilitated by hyperosmolar or inflammatory disruption of the perineurium.

\section{Discussion}

The first part of this study demonstrates that (1) upon intraplantar inoculation with FCA, signs of inflammation appear within a few hours and remain largely confined to the inoculated paw, (2) antinociceptive effects of opioid agonists are detectable in the inflamed paw only, occur at a very early stage and in close temporal correlation to the development of the inflammation, (3) these effects are mediated by local opioid receptors in the paw, and (4) three different types of receptors become active simultaneously.

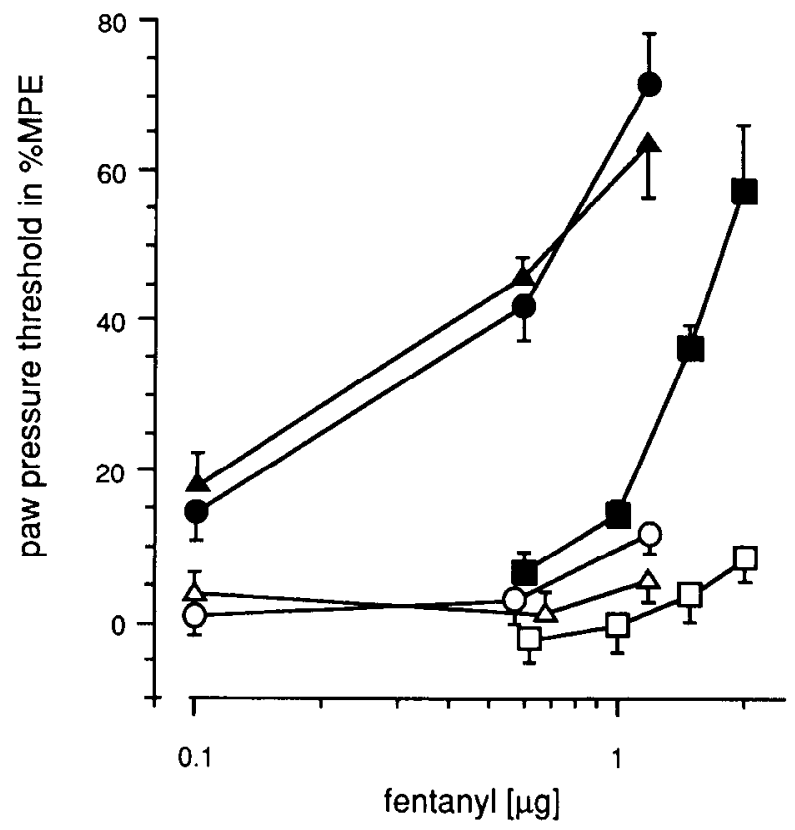

Figure 7. PPT alterations (in \% MPE) after intraplantar administration of fentanyl (solid squares), saline (open squares and triangles) and of fentanyl-mannitol combinations (solid triangles) in normal rats and effects of intraplantar fentanyl in inflamed (solid circles) and noninflamed (open circles) paws of FCA-treated rats. Values are means \pm SEM ( $n=6-7$ per dose). Effective dose ranges of fentanyl are similar in inflamed and mannitol-treated paws ( $p>0.05$, two-factor ANOVA) and significantly lower $(p<0.005$, two-factor ANOVA) than in normal paws.

Previous studies have shown that peripheral antinociceptive effects of opioids are unequivocally more pronounced in inflamed than in noninflamed tissue (for reviews, see Barber and Gottschlich, 1992; Stein, 1993) and that such effects are brought about by an interaction with opioid receptors located on periphcral sensory or autonomic nerves (Bartho et al., 1990; Stein et al., 1990; Taiwo and Levine, 1991). These observations have been ascribed in part to an increase in the number (upregulation) of receptors (Hassan et al., 1993; Schäfer et al., 1994b). Consistent with our present findings, peripheral opioid antinociceptive effects have been reported at very early stages of different inflammatory conditions (reviews in Barber and Gottschlich, 1992; Stein, 1993). At such early stages, however, a de novo synthesis of opioid receptors and axonal transport from the perikaryon to the periphery is not a likely explanation for these effects because this transport requires several days (Hassan et al., 1993). Furthermore, in view of the highly differentiated neuroanatomical and temporal regulation of the synthesis of different opioid peptides under various inflammatory conditions (Iadarola et al., 1988; Millan et al. 1988; Stein et al., 1990; Przewlocka et al., 1992; Przewlocki et al., 1992), it seems unlikely that such a synthesis should initiate simultancously for three different opioid receptor systems. Lastly, we and others have demonstrated opioid receptors on peripheral nerves under normal conditions (LaMotte et al., 1976; Fields et al., 1980; Ninkovic et al., 1982; Stein et al., 1990; Hassan et al., 1993). Therefore, we put forth an alternative hypothesis, namely, that opioid receptors are preexistent on sensory nerves but hardly accessible under normal circumstances and that the disruption of a physical barrier and a subsequent facilitated access for 
agonists contributes to their enhanced antinociceptive effects during the early stages of inflammation.

Under normal circumstances, tight intercellular contacts at the innermost layer of the perineurium preserve homeostasis in the endoneurial tissue embedding peripheral neurons. This layer acts as a diffusion barrier not only for high molecular weight or hydrophilic substances such as HRP and peptides (Kristensson and Olsson, 1971; Rechthand and Rapoport, 1987; Olsson, 1990) but also for lipophilic compounds such as fentanyl and sufentanil (Gissen et al., 1987). This barrier continues up to the peripheral endings of afferent somatic and autonomic nerve fibers (Low, 1976; Olsson, 1990). An exception are noncorpuscular nerve endings, a subgroup of somatic afferents, which terminate either within the perineurium or lack it at their very tips (ca. $0.3 \mathrm{~mm}$ in the cat) (Burkel, 1967; Heppelmann ct al., 1990). Opioid receptors are located not only at the tips of afferent nerve terminals but also within a considerable distance (several millimeters in the rat) therefrom (Stein et al., 1990; Hassan et al., 1993). Furthermore, there is evidence for their location on autonomic fibers (Illes, 1989; Taiwo and Levine, 1991) and along axons (Jurna and Grossman, 1977; Frank, 1985; Hassan et al., 1993). All of the above loci are clearly ensheathed by perineurium (Olsson, 1990) and are potential sites of action for opioids.

Inflammatory conditions entail a deficiency of the perineurial barrier and/or an enhanced permeability of endoneurial capillaries (de la Motte et al., 1975; Rechthand and Rapoport, 1987; Bockman et al., 1988; Powell and Myers, 1989; Olsson, 1990). A similar leakage can be produced experimentally by the extraneural application of hyperosmolar solutions (Kristensson and Olsson, 1976; Weerasuriya et al., 1979; Rechthand and Rapoport, 1987). Consistently, our histochemical experiments demonstrate that HRP, applied extraneurally in vivo, does not penetrate into the endoneurium of cutaneous nerves in noninflamed paws but does so at both early and later stages of the inflammatory reaction. In normal tissue, the perineural administration of either hypertonic saline or mannitol strikingly enhances the passage of HRP into the endoneurium. The fact that $20 \%$ saline induces this increased barrier permeability when given before, but mannitol only when given after HRP suggests that the former has a prolonged and the latter a transient effect, which is consistent with the literature (see below). Thus, we have demonstrated that a deliberate leakage of the perineurial and/or endoneurial capillary barrier can be produced in vivo. Taken together, these findings strongly support the contention that either inflammatory or artificial disruption of the bloodnerve barrier facilitates the access of macromolecules to sensory neurons.

To further confirm this hypothesis, we examined the effects of a hyperosmolar mannitol solution with and without opioid agonists upon nociceptive thresholds in noninflamed and inflamed tissue. Indeed, the last part of this study demonstrates that (1) while mannitol itself is inactive, it enables opioid agonists to produce opioid receptor-specific antinociception in noninflamed paws, (2) this action is dependent on the concentration of mannitol and of short duration, (3) mannitol does not further enhance the effects of opioids in inflamed tissue, and (4) the intact perineurium is not impenetrable but represents a significant barrier even for a lipophilic compound since the effects of fentanyl are markedly potentiated by hyperosmolar or inflammatory perineurial disruption.

Similar to the situation at the blood-brain barrier (Rapoport and Robinson, 1986), the effects of hyperosmolar solutions have been ascribed to a transient shrinkage of perineurial cells with subsequent widening of the zonulae occludentes (Kristensson and Olsson, 1976; Rechthand and Rapoport, 1987). This effect is short lasting, reaches a maximum at certain concentrations of mannitol and declines at higher concentrations (Rapoport et al., 1980; Neuwelt et al., 1986; Butt et al., 1990), which is fully consistent with our observations. This opening of the perineurial barrier can result in an enhanced penetrability for macromolecules and/or ions, which may enable opioid agonists to reach the endoneurium and to interact with neuronal opioid receptors. Alternatively, a change in endoneurial electrolyte concentrations (Myers et al., 1983) or mannitol itself may cause an alteration of the conformation of opioid receptors from an inactive to an active statc and/or a change of the excitability or conductive properties of axons (Rechthand and Rapoport, 1987; Powell and Myers, 1989). The latter mechanism, however, seems unlikely in our experiments, since (1) the effects of mannitolopioid combinations were completely reversible by naloxone and (2) mannitol given alone had no effect, which is consistent with clinical studies describing mannitol as an essentially inert substance (Neuwelt and Dahlborg, 1989). The fact that mannitol did not further enhance opioid antinociception in inflamed paws is consistent with the notion that opioid agonists have free access to their receptors due to an already deficient perineurial barrier.

In summary, we have shown that peripheral opioid analgesia and perineurial disruption coincide during very early stages of an inflammatory reaction and that both can be mimicked by hyperosmolar solutions in normal tissue. These findings have several interesting implications. (1) While initially discovered under inflammatory conditions, peripheral opioid analgcsic cffects can be brought about in normal tissue as well. The hitherto enigmatic observation that such effects are difficult to detect in noninflamed tissue is now explainable. (2) Beyond their particular significance for opioids, these data underscore the important role of the perineurial barrier for the pharmacokinetics of locally applied compounds influencing neuronal function in general, and they demonstrate for the first time that the efficacy of both hydrophilic and lipophilic compounds can be improved dramatically by the concomitant modulation of perineurial permeability. (3) These observations indicate an unrestricted transperineurial passage for peptides in inflammation and thus add a further integral component to our previously outlined concept of a direct communication between immune cell-derived endogenous opioid peptides and sensory nerves resulting in the inhibition of inflammatory pain (Stein et al., 1990, 1993; Schäfer et al., 1994a).

\section{References}

Barber A, Gottschlich R (1992) Opioid agonists and antagonists: an evaluation of their peripheral actions in inflammation. Med Res Rev 12:525-562.

Barthó L, Stein C, Herz A (1990) Involvement of capsaicin-sensitive neurones in hyperalgesia and enhanced opioid antinociception in inflammation. Naunyn Schmiedebergs Arch Pharmacol 342:666-670.

Bockman DE, Büchler M, Malfertheiner P, Beger HG (1988) Analysis of nerves in chronic pancreatitis. Gastroenterology 94:1459-1469.

Burkel WE (1967) The histological fine structure of perineurium. Anat Rec 158:177-190.

Butt AM, Jones HC, Abbott NJ (1990) Electrical resistance across the blood-brain barrier in anaesthetized rats: a developmental study. J Physiol (Lond) 429:47-62.

de la Motte DJ, Hall SM, Allt G (1975) A study of perineurium in peripheral nerve pathology. Acta Neuropathol (Berl) 33:257-270. 
Fields HL, Emson PC, Leigh BK, Gilbert RFT, Iversen LL (1980) Multiple opiate receptor sites on primary afferent fibres. Nature 284: 351-353.

Frank GB (1985) Stereospecific opioid receptors on excitable cell membranes. Can J Physiol Pharmacol 63:1023-1032.

Gissen AJ, Gugino LD, Datta S, Miller J, Covino BG (1987) Effects of fentanyl and sufentanil on peripheral mammalian nerves. Anesth Analg 66:1272-1276.

Hassan AHS, Ableitner A, Stein C, Herz A (1993) Inflammation of the rat paw enhances axonal transport of opioid receptors in the sciatic nerve and increases their density in the inflamed tissue. Neuroscience 55:185-195.

Heppelmann B, Messlinger K, Neiss WF, Schmidt RF (1990) Ultrastructural three-dimensional reconstruction of group III and group IV sensory nerve endings ("free nerve endings") in the knee joint capsule of the cat: evidence for multiple receptive sites. J Comp Neurol 292:103-116.

Iadarola MJ, Brady LS, Draisci G, Dubner R (1988) Enhancement of dynorphin gene expression in spinal cord following experimental inflammation: stimulus specificity, behavioral parameters and opioid receptor binding. Pain 35:313-326.

Illes P (1989) Modulation of transmitter and hormone release by multiple neuronal opioid receptors. Rev Physiol Biochem Pharmacol 112:169-171.

Jurna I, Grossmann W (1977) The effect of morphine on mammalian nerve fibres. Eur J Pharmacol 44:339-348.

Kristensson K, Olsson Y (1971) The perineurium as a diffusion barrier to protein tracers. Differences between mature and immature animals. Acta Neuropathol (Berl) 17:127-138.

Kristensson K, Olsson Y (1976) Osmotic opening of perineurial diffusion barrier in peripheral nerve. Neuropathol Appl Neurobiol 2:479488.

LaMotte C, Pert CB, Snyder SH (1976) Opiate receptor binding in primate spinal cord: distribution and changes after dorsal root section. Brain Res 112:407-412.

Low FN (1976) The perineurium and connective tissue of peripheral nerve. In: The peripheral nerve (Landon DN, ed), pp 159-187. New York: Wiley.

Malmgren L, Olsson Y (1978) A sensitive method for histochemical demonstration of horseradish peroxidase in neurons following retrograde axonal transport. Brain Res 148:279-294.

Millan MJ, Czlonkowski A, Morris B, Stein C, Arendt R, Huber A, Höllt V, Herz A (1988) Inflammation of the hind limb as a model of unilateral localized pain: influence on multiple opioid systems in the spinal cord of the rat. Pain 35:299-312.

Myers RR, Heckman HM, Powell HC (1983) Endoneurial fluid is hypertonic. J Neuropathol Exp Neurol 42:217-224.

Neuwelt EA, Dahlborg SA (1989) Blood-brain barrier disruption in the treatment of brain tumors. Clinical implications. In: Implications of the blood-brain barrier and its manipulation, Vol 2 (Neuwelt EA, ed), pp 195-261. New York: Plenum.

Neuwelt EA, Minna J, Frenkel E, Barnett PA, McCormick CI (1986) Osmotic blood-brain barrier opening to IgM monoclonal antibody in the rat. Am J Physiol 250:R875-R883.

Ninkovic M, Hunt SP, Gleave JRW (1982) Localization of opiate and histamine $\mathrm{H} 1$-receptors in the primary sensory ganglia and spinal cord. Brain Res 241:197-206.

Olsson Y (1990) Microenvironment of the peripheral nervous system under normal and pathological conditions. Crit Rev Neurobiol 5:265311.
Powell HC, Myers RR (1989) The blood-nerve barrier and the pathologic significance of nerve edema. In: Implications of the blood-brain barrier and its manipulation (Neuwelt EA, ed), pp 199-222. New York: Plenum.

Przewlocka B, Lason W, Przewlocki R (1992) Time-dependent changes in the activity of opioid systems in the spinal cord of monoarthritic rats - a release and in situ hybridization study. Neuroscience 46:209216.

Przewlocki R, Hassan AHS, Lason W, Epplen C, Herz A, Stein C (1992) Gene expression and localization of opioid peptides in immune cells of inflamed tissue. functional role in antinociception. Neuroscience 48:491-500.

Rapoport SI, Robinson PJ (1986) Tight-junctional modification as the basis of osmotic opening of the blood-brain barrier. In: The neuronal microenvironment. Ann New York Acad Sci 481:250-267.

Rapoport SI, Fredericks WR, Ohno K, Pettigrew KD (1980) Quantitative aspects of reversible osmotic opening of the blood-brain barrier. Am J Physiol 238:R421-R431.

Rechthand E, Rapoport SI (1987) Regulation of the microenvironment of peripheral nerve: role of the blood-nerve barrier. Prog Neurobiol 28:303-343.

Rosene DL, Mesulam MM (1978) Fixation variables in horseradish peroxidase neurohistochemistry. I. The effects of fixation time and perfusion procedures upon enzyme activity. J Histochem Cytochem 26:28-39.

Schäfer M, Carter L, Stein C (1994a) Interleukin-1 $\beta$ and corticotropinreleasing-factor inhibit pain by releasing opioids from immune cells in inflamed tissue. Proc Natl Acad Sci USA 91:4219-4223.

Schäfer M, Imai Y, Mousa SA, Antonijevic I, UhI GR, Stein C (1994b) Pcriphcral mu-opioid receptors during inflammation: enhanced synthesis and accessibility increase antinociceptive efficacy of opioids. Soc Neurosci Abstr, in press.

Stein C (1993) Peripheral mechanisms of opioid analgesia. Anesth Analg 76:182-191.

Stein C, Millan MJ, Shippenberg TS, Herz A (1988) Peripheral effect of fentanyl upon nociception in inflamed tissue of the rat. Neurosci Lett 84:225-228.

Stein C, Millan MJ, Shippenberg TS, Peter K, Herz A (1989) Peripheral opioid receptors mediating antinociception in inflammation. Evidence for involvement of mu, delta and kappa receptors. J Pharmacol Exp Ther 248:1269-1275.

Stein C, Hassan AHS, Przewlocki R, Gramsch C, Peter K, Herz A (1990) Opioids from immunocytes interact with receptors on sensory nerves to inhibit nociception in inflammation. Proc Natl Acad Sci USA 87:5935-5939.

Stein C, Hassan AHS, Lehrberger K, Giefing J, Yassouridis A (1993) Local analgesic effect of endogenous opioid peptides. Lancet 342:321324.

Streinzer W, Krammer EB (1986) Horseradish peroxidase histochemistry on mounted sections from embedded specimen: a simple method for serial reconstruction of neuronal projections. J Neurosci Methods 17:297-301.

Taiwo YO, Levine JD (1991) Kappa and delta-opioids block sympathetically dependent hyperalgesia. J Neurosci 11:928-932.

Wall PD (1993) Vigilance in defense of animal welfare. Pain 54:239.

Weerasuriya A, Rapoport SI, Taylor RE (1979) Modification of permeability of frog perineurium to $\left({ }^{14} \mathrm{C}\right)$-sucrose by stretch and hypertonicity. Brain Res 173:503-512.

Zar JH (1984) Biostatistical analysis. Englewood Cliffs, NJ: Prentice Hall. 